\title{
Plumbagin-Loaded Glycerosome Gel as Topical Delivery System for Skin Cancer Therapy
}

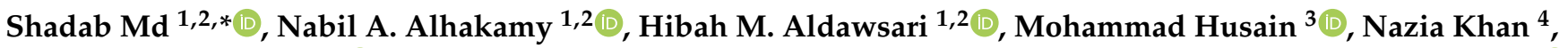 \\ Mohamed A. Alfaleh ${ }^{1,5}{ }^{(0}$, Hani Z. Asfour ${ }^{6}$, Yassine Riadi ${ }^{7}$, Anwar L. Bilgrami ${ }^{8}$ and Md Habban Akhter ${ }^{9, *}$
}

1 Department of Pharmaceutics, Faculty of Pharmacy, King Abdulaziz University, Jeddah 21589, Saudi Arabia; nalhakamy@kau.edu.sa (N.A.A.); haldosari@kau.edu.sa (H.M.A.); maalfaleh@kau.edu.sa (M.A.A.)

2 Center of Excellence for Drug Research \& Pharmaceutical Industries, King Abdulaziz University, Jeddah 21589, Saudi Arabia

3 Department of Biotechnology, Jamia Millia Islamia (Central University), New Delhi 110025, India; mhusain2@jmi.ac.in

4 Department of Pharmaceutics, School of Pharmaceutical Education and Research, Jamia Hamdard, New Delhi 110062, India; khannaziaspn91@gmail.com

5 Vaccines and Immunotherapy Unit, King Fahd Medical Research Center, King Abdulaziz University, Jeddah 21589, Saudi Arabia

6 Department of Medical Microbiology and Parasitology, Faculty of Medicine, King Abdulaziz University, Jeddah 21589, Saudi Arabia; hasfour@kau.edu.sa

7 Department of Pharmaceutical Chemistry, College of Pharmacy, Prince Sattam Bin Abdulaziz University, Al-Kharj 11942, Saudi Arabia; yassinriadi@yahoo.fr

check for

updates

Citation: Md, S.; Alhakamy, N.A.; Aldawsari, H.M.; Husain, M.; Khan, N.; Alfaleh, M.A.; Asfour, H.Z.; Riadi, Y.; Bilgrami, A.L.; Akhter, M.H.

Plumbagin-Loaded Glycerosome Gel as Topical Delivery System for Skin Cancer Therapy. Polymers 2021, 13, 923. https://doi.org/10.3390/ polym13060923

Academic Editor: Christian Wiraja

Received: 27 February 2021

Accepted: 15 March 2021

Published: 17 March 2021

Publisher's Note: MDPI stays neutral with regard to jurisdictional claims in published maps and institutional affiliations.

Copyright: (c) 2021 by the authors. Licensee MDPI, Basel, Switzerland. This article is an open access article distributed under the terms and conditions of the Creative Commons Attribution (CC BY) license (https:/ / creativecommons.org/licenses/by/ $4.0 /)$.
8 Department of Entomology, Rutgers University, New Brunswick, NJ 08901, USA; anwarbil@scarletmail.rutgers.edu

9 Faculty of Pharmacy, DIT University, Dehradun 248009, India

* Correspondence: shaque@kau.edu.sa (S.M.); habban.akhter@dituniversity.edu.in (M.H.A.)

Abstract: Plumbagin (PLM) is a phytochemical which has shown cytotoxicity against of cancer cells both in vitro and in vivo. However, the clinical application of PLM has been hindered due to poor aqueous solubility and low bioavailability. The aim of the present study was to develop, optimize and evaluate PLM-loaded glycerosome (GM) gel and compare with conventional liposome (CL) for therapeutic efficacy against skin cancer. The GM formulations were optimized by employing design expert software by 3-level 3-factor design. The prepared GMs were characterized in vitro for vesicle size, size distribution, zeta potential, vesicle deformability, drug release, skin permeation, retention, texture, antioxidant and cytotoxicity activities. The optimized formulation showed a vesicle size of $119.20 \pm 15.67 \mathrm{~nm}$ with a polydispersity index (PDI) of $0.145 \pm 0.02$, the zeta potential of $-27 \pm 5.12 \mathrm{mV}$ and entrapment efficiency of $76.42 \pm 9.98 \%$. The optimized PLM-loaded GM formulation was transformed into a pre-formed gel which was prepared using Carbopol 934 polymer. The drug diffusion fluxes of CL gel and GM-loaded gel were $23.31 \pm 6.0$ and $79.43 \pm 12.43 \mu \mathrm{g} / \mathrm{cm}^{2} / \mathrm{h}$, respectively. The result of texture analysis revealed the adequate hardness, cohesiveness, consistency, and viscosity of the developed GM-loaded gel compared to CL gel. The confocal images showed that glycerosomal gel has deeper skin layer penetration as compared to the control solution. GM-loaded gel treated rat skin showed significantly $(p<0.05)$ higher drug accumulation in the dermis, higher cytotoxicity and higher antioxidant activity as compared to CL gel and PLM suspension. Thus, findings revealed that novel GM-loaded gel could be potential carriers for therapeutic intervention in skin cancer.

Keywords: Box-Behnken design; confocal microscopy; liposome; gel; plumbagin; skin cancer

\section{Introduction}

Cancer as a life-threatening disease is increasing in prevalence worldwide. It caused an estimated 9.6 million deaths in 2018 with an anticipated mortality of 16.4 million by 
2040 [1]. Skin cancer is a complex and common malignancy, spreading worldwide with alarming mortality statistics. The common skin cancers are classified as non-melanoma and melanoma skin cancer. The non-melanoma skin cancer represented by basal cell carcinoma, and squamous cell carcinoma. The skin cancer eruption leads to deformation of skin cells and may result in systemic migration and metastases if not diagnosed promptly [2]. The pathogenesis of skin cancer is multi-factorial, but the prevalent risk factor is long exposure to carcinogenic and inflammatory agent. Indeed, the long exposure to UV radiation (UVA and UVB) also leads to the development of skin cancer due to impairment of genetic material, activating tumor promoter genes, inflammation and oxidative stress [3-5]. The current therapeutic approach involves the application of chemotherapy, radiotherapy and surgery.

Skin provides a large surface area for the topical delivery of a vast number of therapeutic formulations. To overcome this barrier, several strategies have been developed. The strategies include polymeric, organic, and inorganic nanoparticles, liposomes, niosomes, carbon tubes, micelles, and quantum dots including, ultrasound-assisted delivery, iontophoresis and electroporation [6-9]. The drug-loaded nanocarrier passively accumulated neighboring to tumor tissues due to poor lymphatic drainage and vacularization. It provides sustained and local drug delivery to the tumor microenvironment as desirable for treatment of cancer cells. For potential eradication and significant apoptosis of tumor cells, long exposure of therapeutics in specific area of skin is preferably required $[4,10]$. Conventional liposomes as a vesicular drug delivery system lack the ability to provide sufficient drug release and deeper penetration across the skin, thereby limiting their therapeutic efficacy. This major drawback led to research of novel vesicular carriers resulting in modification of composition of liposomes to increase drug delivery and efficacy [11].

In this context, some authors modified the composition of specially designed vesicular carriers to enhance the permeation and penetration into the deeper layers of skin. Thus, novel, modified vesicular carriers so-called ultradeformable or elastic liposomes such as transferosome, ethosomes, niosomes, and invasomes have been successfully evaluated and introduced in drug delivery applications [12].

Ethosomes, when administered, fuse with the cutaneous layer of skin due to the interaction of ethanol with skin lipid. The permeation of drug is enhanced into the epidermal layer of skin owing to elastic deformation process [13]. However, the alcoholic interaction with lipid molecules of skin leads to decreased transition temperature in stratum corneum. It further leads to phase separation and crystal-phase transformation of solid and liquid lipids. Apart from these, the alcoholic content in ethosome causes skin irritation. On the contrary, GM causes no harm and is completely accepted after topical application [14,15]. Furthermore, $>20 \%$ glycerol stabilizes the GM vesicle system. The high viscosity and hygroscopic nature improve flexibility and fluidity of the lipid bilayer. This nature allows GM to squeeze through topical barrier resulting in higher drug release and improved permeation and efficacy when used topically or transdermally [16].

Engineered hydrogel mimics the extra cellular matrix of the epidermal tissue of skin due to better structural and mechanical strength. The nanosized hydrogel as polymeric 3D dimensional network in aqueous dispersion is formed by hydrophilic polymer chains that are chemically or physically cross connected [17]. Gels are intelligently explored in active/passive cancer targeting due to their tailor surface, tunable size, ease of preparation and high encapsulation. It is prominently internalized in the target cells, prevents accumulation in the non-target tissues, minimize side effects and reduce therapeutic dose [18].

(5-hydroxy-2-methyl-1, 4-naphthoquinone) extracted from root of plant Plumbago zeylanica having a number of potential therapeutic effects like anti-malarial, anti-microbial [19] and anti-inflammatory effects $[10,20]$. In a number of cancers, including liver, breast, esophagus, colon, prostate, brain, and lung cancer, plumbagin have shown in vitro/in vivo anti-proliferative and chemo-preventive effects $[10,20,21]$. The tumor inhibitory mechanism of plumbagin is based on several molecular signaling pathways which are crucial in cell proliferation, invasion, survival and metastasis. It suppresses these major signal trans- 
duction pathways STAT3, mTOR/AKT, and NF-KB which plays pivotal role in the growth, development and progress of cancer. Plumbagin retarded UV-ray induced carcinoma in squamous region of skin in mice [22-24]. The activation of STAT3 signal pathway is associated $70 \%$ case of melanoma cancer [25]. Plumbagin also suppresses hyper-pigmentation of skin by inhibiting an $\alpha$-melanocyte-stimulating hormone and inhibited tyrosinase activity in B16-F10 melanoma cells [26]. Ti and coworkers also reported that plumbagin do not induce cytotoxicity in normal lens epithelial cells (B3) and normal human keratinocytes (HaCaT) cells at lower concentration (1-5 $\mu \mathrm{M})$ suggesting plumbagin is safe for skin application [26].

The term "glycerosome" was first acquainted by Manca and associates for topical delivery of diclofenac. It is a versatile drug delivery carrier system which is a modification of liposomes. They are small or large unilamellar or multilamellar lipid vesicles composed of phospholipids, water, and varying concentrations of glycerol (preferably 20 to $30 \% w / v$ ). Additionally, they are nontoxic and accepted for topical application $[16,27]$. The lipid layer in GM is more flexible and possess high fluidity suitable for topical and transdermal drug delivery. The glycerol in these vesicles improves deformability index and thus increases skin permeation and penetration of therapeutics. Cholesterol enhances the stability of GM as well as maintains the lipid membrane integrity by causing barrier to the aqueous phase. When GM dispersed in aqueous phase, phospholipid rapidly arranges themselves as bi-layer vesicles [28,29].

The present study involves the optimization and formulation of PLM-loaded GM using Box-Behnken Design. The independent variables were phospholipid, cholesterol, and glycerol concentration while the dependent variables were vesicle size, entrapment efficiency and drug permeation/flux of PLM, respectively. The optimized formulation was characterized for its size, charge and morphology, texture, drug permeation/flux, drug release, permeation, and retention. Additionally, characterizations based on cytotoxicity were also evaluated. During the study it was speculated that incorporating PLM into GM could enhance drug loading and entrapment with improved aqueous solubility, thereby prolonging systemic availability in sustained-release manner; a combination of all these properties would consequently increase the therapeutic efficacy of PLM and reduce untoward effects.

\section{Materials and Methods}

\subsection{Materials}

PLM, glycerol, rhodamine B and cholesterol were purchased from Sigma-Aldrich (St. Louis, MO, USA). Phospholipid $90 \mathrm{G}$ was procured by Phospholipid GmbH, Germany. The in vitro cell line B16-F10 cells were obtained from National Centre for Cell Science (NCCS) (Pune, India). Dulbecco's modified Eagle's medium (DMEM), antibiotics, Foetal Bovine Serum, and MTT reagent were purchased from Gibco (Gaithersburg, MD, USA). Analytical grade was used for HPLC water, solvents and chemicals used in the analysis.

\subsection{Design and Development of Nanosystem}

Preparation of PLM-Loaded Nanosystems

The PLM-loaded CLs were developed by thin film hydration technique [27,30]. A weighted amount of PLM $(5 \mathrm{mg} / \mathrm{mL})$ was dissolved in chloroform containing $~ 1 \%$ of ethanol along with phospholipid $(15.0 \mathrm{mg} / \mathrm{mL})$ and cholesterol $(4.0 \mathrm{mg} / \mathrm{mL})$ in a roundbottom flask and mechanically stirred at $40^{\circ} \mathrm{C}$ for $1 \mathrm{~h}$. Under reduced pressure, the mixture was evaporated using a rotary evaporator (Buchi Labortechnik AG, New Castle, MA, USA), resulting formation of transparent lipid film around the round bottom flask, and traces of solvent were extracted overnight under vacuum. Further, the lipid film was dried and hydrated at $\mathrm{pH} 7.4$ for $1 \mathrm{~h}$ in phosphate buffer saline (PBS) for PLM-loaded CLs. Subsequently, the film suspension was probe sonicated (Hielscher Ultrasonics, Berlin, Germany) for $1.5 \mathrm{~min}$ at $90 \%$ amplitude and ultracentrifuged at $7500 \times \mathrm{g}$ for $10 \mathrm{~min}$ at $4{ }^{\circ} \mathrm{C}$ to get rid of unentrapped drug excess in solvent and lyophilized for future application. For 
PLM-loaded GMs, the obtained lipid films were hydrated with glycerol-water mixture $\left(30 \% w / v\right.$ glycerol) in two successions followed by mechanical agitation for $1 \mathrm{~h}$ at $40{ }^{\circ} \mathrm{C}$. Finally, the vesicle dispersions were sonicated for half cycle, i.e., $60 \mathrm{~s}$ with $3 \mathrm{~s}$ layoff period for every $5 \mathrm{~s}$. The developed formulation centrifuged at $7500 \times \mathrm{g}$ for $10 \mathrm{~min}$ at $4{ }^{\circ} \mathrm{C}$ to move out unentrapped drug excess, and lyophized for further use.

\subsection{Box-Behnken Design}

Box-Behnken Design Expert (Design-Expert VR Software Version 10, State-Ease Inc., Minneapolis, MN, USA) software was used for optimization of PLM-loaded GMs and CLs $[13,31,32]$. Based on the design expert software, 17 total runs were generated with 3-level and 3-factor experimental model for optimization of the GMs formulation. The independent and dependent variables are shown in Table 1. Among the various models like 2FI, cubic, linear, and quadratic, the best fit model was analyzed according to ANOVA for statistical design. The significant F-value, low PRESS value, lack of fit $(p>0.05)$ determined the best fitting model.

Table 1. Box-Behnken design experimental dependent and independent variables with levels (low, medium and high) employed in the fabrication of PLM-loaded GMs.

\begin{tabular}{cccc}
\hline Independent Variables & \multicolumn{3}{c}{ Level Used } \\
\cline { 2 - 4 } & Low (-1) & Medium (0) & High (+1) \\
\hline $\mathrm{X}_{1}$ : Phospholipid conc. $(\mathrm{mg})$ & 15 & 22.5 & 30 \\
\hline $\mathrm{X}_{2}$ : Cholesterol $(\mathrm{mg})$ & 1 & 2.5 & 4 \\
\hline $\mathrm{X}_{3}$ : Glycerol & 10 & 20 \\
\hline Dependent variables & & Minimize \\
\hline $\mathrm{Y}_{1}:$ Vesicles size $(\mathrm{nm})$ & Maximize \\
\hline $\mathrm{Y}_{2}:$ Entrapment efficiency $(\%)$ & Maximize \\
\hline $\mathrm{Y}_{3}:$ Drug permeation/Flux $\left(\mu \mathrm{g} / \mathrm{cm}^{2} / \mathrm{h}\right)$ &
\end{tabular}

\subsection{Characterization of Nanosystem Dispersion}

\subsubsection{Particle size, Zeta Potential and Morphological Analysis}

The Zetasizer-ZSP (Malvern Instruments, Worcestershire, UK) work on the dynamic light scattering was used to evaluate the vesicle size, polydispersity index (PDI) and zeta potential of optimized PLM-loaded CLs, PLM-loaded GMs and rhodamine-loaded glycerosome. The formulations were diluted with deionized water and analysed in triplicate $(n=3)$. The actual size of PLM-loaded GM and CL and were measured by transmission electron microscopy (TEM, JEOL JEM1010, Tokyo, Japan). The drug-loaded GMs and CLs sample $(1 \mathrm{mg} / \mathrm{mL})$ was diluted in deionized water. The sample volume of $10 \mu \mathrm{L}$ was then applied on carbon-coated copper grid. The extra water over copper grid was bumped off and dried. It was then negatively stained with $1 \%$ phosphotungstic acid and tested at $10-100$-fold enlargements operating at an accelerating voltage of $80 \mathrm{kV}$ under the TEM.

\subsubsection{Entrapment Efficiency and Drug Loading}

The entrapped amount of PLM in GMs, CLs and fluorescent dye in glycerosome before lyophilization was estimated by high-speed centrifugation system at $7500 \times g$ for $10 \mathrm{~min}$ at $4{ }^{\circ} \mathrm{C}[33,34]$. After centrifugation, the clear aliquot was removed, filtered and PLM content was analyzed by HPLC analysis. In brief, the separation of analyte using HPLC system (Shimadzu, Japan) was achieved on Agilent $C_{18}$ column of dimension $5 \mu \mathrm{m}$, $250 \mathrm{~mm} \times 4.5 \mathrm{~mm}$ i.d. The other components of HPLC system were quaternary LC-10 AVP pumps, SPD-10AVP HPLC UV-detector. PLM was estimated at a wavelength of $265 \mathrm{~nm}$ in binary mobile phase comprised of methanol and sodium dihydrogen phosphate phase $(9: 1 v / v)$ using calibration curve [35]. The calibration curve was constructed in the 
linearity range of $1-10 \mu \mathrm{g} / \mathrm{mL}$. The entrapment efficiency of the optimized formulation was calculated by using formula. The obtained numeric for the calibration curve was $Y=0.096 X+0.021$ with regression coefficient value $\left(R^{2}=0.998\right)$.

$\%$ Entrapment efficiency $=$ Drug content $(A-B) /$ Total amount of drug $\times 100$

$\%$ Drug loading $=$ Drug content $(\mathrm{A}-\mathrm{B}) /$ Total weight of glycerosome $\times 100$

where $\mathrm{A}$ is the total amount of drug and B is the amount of drug analyzed in the super natant using HPLC [34].

\subsubsection{In Vitro Drug Release and Kinetic Studies}

In vitro drug release study was performed in PBS with an acidic $\mathrm{pH} 4.5$ and $\mathrm{PBS} \mathrm{pH}$ 7.4. The acidic range is the $\mathrm{pH}$ of the skin and $\mathrm{pH}$ at the tumor site [36]. The analysis was carried out using dialysis bag techniques. The weighed amount of PLM-loaded GMs, CLs and PLM suspension were placed on the dialysis membrane (MWCO, $12000 \mathrm{Da}$, Sigma-Aldrich, St. Louis, MO, USA) and immersed in a beaker filled with $100 \mathrm{~mL}$ of PBS solution. The beaker placed in a thermostatically controlled shaking water bath at a temperature $37 \pm 0.5^{\circ} \mathrm{C}$ and release of the drug from formulation was examined at the mentioned $\mathrm{pH}$ values separately. At regular intervals of time $(0,1,2,4,6,8$ \& $12 \mathrm{~h}), 3 \mathrm{~mL}$ of PBS was withdrawn and was reinstated with the same amount of fresh PBS to maintain sink condition. The samples were analyzed using HPLC. In release kinetic study, drug release profile from formulation was fitted into zero order, first order, Korsmeyer-Peppas, Higuchi, and Hixson-Crowell kinetic models and the best one was discriminated based on the correlation coefficient $\left(\mathrm{R}^{2} \sim 1\right)$ value.

\subsection{Encapsulation of the Nanosystem into a Preformed Gels}

The gel base was prepared as the method described in our earlier work [13]. 1.0\% $w / w$ carbopol 934 was continuously stirred for $2 \mathrm{~h}$ using magnetic bead in $10 \mathrm{~mL}$ of distilled water separately for both PLM-loaded GMs and CLs. Accordingly, propylene glycol, methyl paraben, and triethanolamine were added with uninterrupted stirring until a transparent gel formed. The PLM-loaded GMs and CLs were injected continuously with stirring into the corresponding pre-formed gel base and labeled them as GM-loaded gel and CL gel. The gel texture analyzer was used to measure the texture of developed gels (TA.XT Plus Texture Analyzer, Stable Micro Systems Ltd., Surrey, UK). The spreadability of gels were measured by placing $500 \mathrm{mg}$ of both CLs and GM gels separately in-between the glass slides upto a diameter of $2 \mathrm{~cm}$. Thereafter, the $0.5 \mathrm{~kg}$ of weight was placed on the upper glass slide for the duration of $5 \mathrm{~min}$ and gels spreading were determined.

\subsection{Skin Permeation Studies of GM-Loaded Gels}

The experiments were performed using fabricated Franz diffusion cell with an effective surface area of diffusion $0.750 \mathrm{~cm}^{2}$. The dorsal surface of rat skin was excised with fatty layers removed surgically, washed with alcohol and temporary stored at $-80^{\circ} \mathrm{C}$. Before commencing the permeation study, the stored rat skin was equilibrated in PBS for $2 \mathrm{~h}$ at room temperature. The Franz diffusion cells decorated the skin specimenssecurely between donor and receptor compartments with the stratum corneum (SC) side facing the donor compartment. Prior to the study, receptor compartment was filled with $7.5 \mathrm{~mL}$ of PBS solution and stirred continuously with a small magnetic bead at $500 \mathrm{rpm}$, maintained at a temperature of $37 \pm 0.5^{\circ} \mathrm{C}$. GM-loaded gels, CL gels, PLM suspension (each $1 \mathrm{~mL}$ ) were placed onto the surface of skin and at regular intervals of time, i.e., $0,1,2,3,4,6,8,12$, 14, 16, 20 and $24 \mathrm{~h}, 1 \mathrm{~mL}$ of solution was withdrawn from the receiving compartment and same amount was replaced with fresh solution. The drug content was analyzed by HPLC analysis. 


\subsection{Drug Retention Study of GM-Loaded Gels}

For drug retention study, the mounted skin was removed from Franz diffusion cell, washed, cleaned for adhered drug particles and further subjected to tape stripping technique for removal of SC from dermal layer using scotch crystal tape [37]. Furthermore, the epidermis was separated from dermis by applying surgical sterile scalpel. The tissue protein extracting reagent (T-PER) solution in the ratio of tissue: T-PER $(1: 10 w / v)$ was applied for ameliorating extraction capacity from skin and probe sonicated for $5 \mathrm{~min}$. Henceforth, the tap strips, dermis and epidermis were transferred into methanol, well sonicated to extract the drug and subsequently analyzed by HPLC.

\subsection{Confocal Microscopy of Rhodamine B-Loaded GM}

To validate the drug release and distribution from GMs formulation into different layer of skin, confocal microscopy was performed which required entrapment of rhodamine B fluorescent dye into glycerosome instead of drug. GMs were loaded with $0.02 \% w / v$ fluorescent dye instead of drug in the preparation of GM by thin film hydration technique and applied onto the skin. In this experiment, processed animal skin was mounted on the Franz diffusion cell of which stratum corneum of skin was facing to donor compartment. The rhodamine B-loaded GMs $(1 \mathrm{~mL})$ was transferred on the donor compartment and release of probe dye in the receptor was checked for the same duration as performed in skin permeation study. The receptor compartment was filled with $6 \mathrm{~mL}$ of PBS, $\mathrm{pH} 7.4$ and the temperature of medium in the diffusion cell was asserted at $32 \pm 0.5^{\circ} \mathrm{C}$. Post completion of study, skin was gently wiped with deionized water (HPLC grade) and mounted on the glass slide with a drop of glycerin and observed under confocal microscope with excitation ( $\lambda$ ex) and emission wavelength $(\lambda \mathrm{em})$ was set at $540 \mathrm{~nm}$ and $630 \mathrm{~nm}$ applying argon laser beam and $65 \times$ objective lens (EC-Plan Neofluar $65 \times / 01.40$ Oil DICM27). The distribution and penetration depth of rhodamine $B$ dye into the different layers of skin from GM compared with rhodamine B solution. The z-axis of confocal microscope optically analyzes the fluorescent permeation through the skin layers.

\subsection{Cytotoxicity Assessment}

The cell viability assessment of GM-loaded gels, CL gels, equivalent dose of PLM suspension, blank GMs and blank CLs were performed using MTT assay in murine melanoma cell lines (B16-F10). The mature cells were seeded in 96 well plates (cell density, 5000 cells/well) in $100 \mu \mathrm{L}$ of Dulbecco's Modified Eagle's Medium (DMEM) culture media to allow cell adherence. Subsequently, the cells were incubated in humidified chamber at $37^{\circ} \mathrm{C}$ with $100 \%$ relative humidity furnished with $5 \% \mathrm{CO}_{2}$. At the end of $24 \mathrm{~h}$, culture medium was discarded and treated with varying concentrations of $2.5,5,7.5,10 \mu \mathrm{M}$ of PLM suspension, CL, and GM-loaded gels. Untreated cells were cultured in complete media and considered as control which is 100\% cell viable. Accompanied by 24,48 and $72 \mathrm{~h}$ of treatment, $250 \mu \mathrm{L}$ of MTT reagent was added into well plate and humidified for $2 \mathrm{~h}$. Further, $150 \mu \mathrm{L}$ of DMSO was added to dissolve formazan crystals (indicating purple colour) as a means of counting viable cells. The absorbance of the specimen on plates was examined on Microplate Reader (BioTek Synergy HT) at $550 \mathrm{~nm}$ and \% cell viability was determined [38].

\subsection{In Vitro Radical Scavenging Assay}

The DPPH (2, 2-diphenyl-1-picryl-hydrazyl) radical scavenging power of PLM in optimized GM-loaded gels was determined in accordance with the developed protocol [39]. The GM-loaded gels $(100 \mu \mathrm{L})$ and PLM suspension $(100 \mu \mathrm{L})$ were mixed with $3.9 \mathrm{~mL}$ of $0.025 \%$ DPPH solution with vigorous shaking, incubated for $30 \mathrm{~min}$ at $28^{\circ} \mathrm{C}$ and quantified by UV-spectrophotometry at $517 \mathrm{~nm}$. The free radical scavenging power of optimized GM-loaded gels was estimated corresponding to reduced optical density with control and served as an indication of free radical scavenging power of the formulation. The reduced 
DPPH concentration was measured by plotting calibration curve of Trolox as standard and the antioxidant power was assessed in TEAC as $\mu \mathrm{g}$ Trolox equivalent/g of sample.

\subsection{Statistical Analysis}

The data analysis was performed using analysis of variance (ANOVA) followed by Tukey Kramer analysis for multiple comparison among the groups using GraphPad Prism 7.00 software. Student's $t$-test was used as comparison between two groups. The level of significance was considered when $p<0.05$.

\section{Results and Discussions}

\subsection{Optimization of PLM-Loaded GM by Statistical Design}

Response surface morphology is extensively employed for the optimization of nanoformulation. Among the various statistical experimental designs, Box-Behnken design is an efficient optimization technique used frequently for comparison with conventional optimization procedures. It is largely explored owing to lesser number of experiments and evaluation in optimum time period. The independent variables and their impact on the response used herein for the optimization and development process were based on the significant preliminary observation.

It has been shown that glycerol $10 \%$ or lesser produced vesicles with reduced flexibility, prompt deformation and may have lower skin penetration. As the concentration of glycerol increases in the formulation, the increasing elasticity of vesicles were observed and at $30 \%$ glycerol concentration the GM were more elastic and resisted deformation. At this concentration glycerol may act as edge activator at phospholipid bilayer [40]. The glycerol content in the GM formulation makes the preparation irritant free on topical application as caused by ethanol in ethosome lipid formulation. The cholesterol in GM formulation is added to ameliorate stability in lipid bilayer, for modifying the surface charge and prevention of vesicle aggregation [16]. The experimental runs with \% compositions of individual components and their responses are recorded in Table 2.

Table 2. Formulations with composition of individual independent variables and observe responses of PLM-loaded glycerosome in Box-Behnken design.

\begin{tabular}{|c|c|c|c|c|c|c|}
\hline \multirow{2}{*}{ Formulation No } & \multicolumn{3}{|c|}{ Independent Variables } & \multicolumn{3}{|c|}{ Observe Responses } \\
\hline & $X_{1}$ (mg) & $\mathrm{X}_{2}(\% w / v)$ & $\mathrm{X}_{3}(\% w / v)$ & $\mathrm{Y}_{1}(\mathrm{~nm})$ & $Y_{2}(\%)$ & $Y_{3}$ \\
\hline FL1 & 22.50 & 2.50 & 20.00 & $160.00 \pm 16.30$ & $74.00 \pm 3.20$ & $69.00 \pm 6.80$ \\
\hline FL2 & 22.50 & 2.50 & 20.00 & $167.00 \pm 17.10$ & $73.00 \pm 5.30$ & $73.00 \pm 6.10$ \\
\hline FL3 & 15.00 & 2.50 & 10.00 & $96.00 \pm 9.40$ & $63.00 \pm 7.50$ & $44.00 \pm 4.30$ \\
\hline FL4 & 22.50 & 2.50 & 20.00 & $163.00 \pm 15.20$ & $77.00 \pm 8.60$ & $72.00 \pm 6.50$ \\
\hline FL5 & 30.00 & 2.50 & 30.00 & $190.00 \pm 18.30$ & $84.00 \pm 9.10$ & $84.00 \pm 9.90$ \\
\hline FL6 & 30.00 & 4.00 & 20.00 & $200.00 \pm 18.40$ & $82.00 \pm 8.60$ & $80.00 \pm 8.60$ \\
\hline FL7 & 15.00 & 2.50 & 30.00 & $88.00 \pm 6.60$ & $68.00 \pm 7.40$ & $74.00 \pm 5.80$ \\
\hline FL8 & 30.00 & 2.50 & 10.00 & $182.00 \pm 14.40$ & $65.00 \pm 6.60$ & $50.00 \pm 4.60$ \\
\hline FL9 & 22.50 & 1.00 & 10.00 & $150.00 \pm 12.70$ & $61.00 \pm 6.90$ & $47.00 \pm 4.60$ \\
\hline FL10 & 22.50 & 1.00 & 30.00 & $152.00 \pm 10.50$ & $71.00 \pm 7.40$ & $77.00 \pm 8.60$ \\
\hline FL11 & 22.50 & 4.00 & 10.00 & $172.00 \pm 16.80$ & $59.00 \pm 4.20$ & $54.00 \pm 5.90$ \\
\hline FL12 & 30.00 & 1.00 & 20.00 & $180.00 \pm 15.00$ & $78.00 \pm 9.50$ & $76.00 \pm 9.50$ \\
\hline FL13 & 22.50 & 4.00 & 30.00 & $176.00 \pm 16.80$ & $80.00 \pm 7.80$ & $85.00 \pm 9.90$ \\
\hline FL14 & 15.00 & 1.00 & 20.00 & $82.23 \pm 4.70$ & $67.00 \pm 7.60$ & $67.00 \pm 6.70$ \\
\hline FL15 & 15.00 & 4.00 & 20.00 & $115.00 \pm 8.50$ & $73.00 \pm 6.80$ & $68.00 \pm 7.90$ \\
\hline FL16 & 22.50 & 2.50 & 20.00 & $157.00 \pm 10.80$ & $78.00 \pm 7.30$ & $78.00 \pm 8.80$ \\
\hline FL17 & 22.50 & 2.50 & 20.00 & $161.00 \pm 13.50$ & $75.30 \pm 9.20$ & $72.00 \pm 8.30$ \\
\hline
\end{tabular}

$\mathrm{X}_{1}$ : Phospholipid (mg); $\mathrm{X}_{2}$ : Cholesterol $(\% w / v) ; \mathrm{X}_{3}$ : Glycerol $(\% w / v) ; \mathrm{Y}_{1}$ : Vesicles size $(\mathrm{nm}) ; \mathrm{Y}_{2}$ : Entrapment efficiency $(\%) ; Y_{3}$ : Drug diffusion Flux $\left(\mu \mathrm{g} / \mathrm{cm}^{2} / \mathrm{h}\right)$. 
The dependent variables were subjected to numerical models fit analysis, for their individual, interaction and quadratic effects. The different models, i.e., cubic, linear, 2FI and quadratic models, the best fitted model was found to be quadratic model. The optimum value of different responses vesicle size, entrapment efficiency, and flux were recorded on the criteria of desirability. The regression analysis of responses, vesicle size $\left(\mathrm{Y}_{1}\right)$, entrapment efficiency $\left(\mathrm{Y}_{2}\right)$ and flux $\left(\mathrm{Y}_{3}\right)$ for fitting to quadratic model are expressed in Table 3 .

The 3-D response surface curve showing relative effects of independent variables on responses $Y_{1}, Y_{2}$ and $Y_{3}$ are established in Figure 1A-C. The statistical plot expressing the correlation between actual vs. predicted value for the responses and their residual plot are indicated in Figure 2A-F.
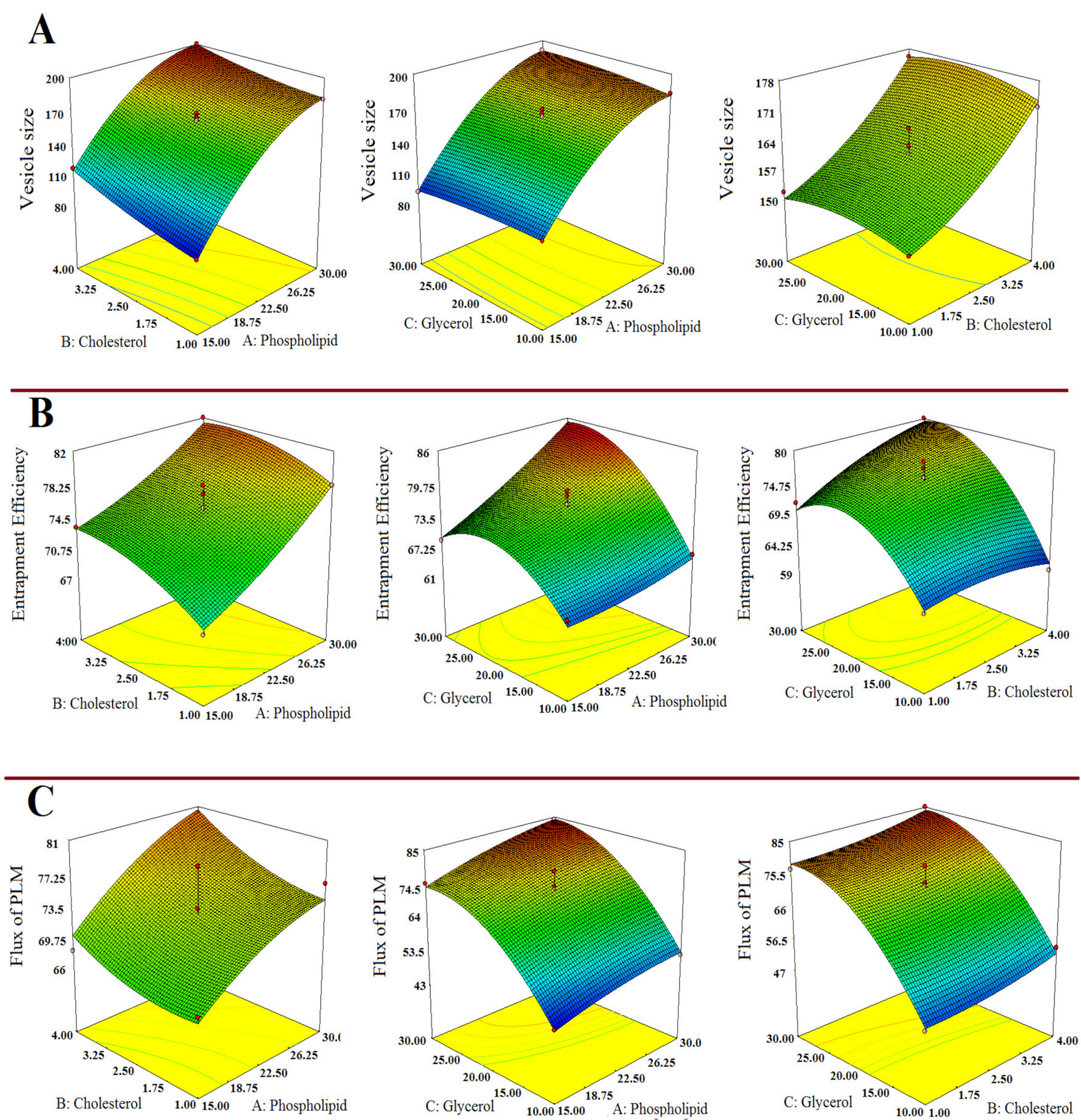

Figure 1. Response surface morphological plots indicating the comparative effects of independent variables, i.e., Phospholipid conc. (mg); Cholesterol conc. (mg); and Glycerol conc. (\% $w / v)$ on (A) Vesicles size, (B) \% Entrapment efficiency and (C) Flux of PLM. 
$\mathbf{A}$

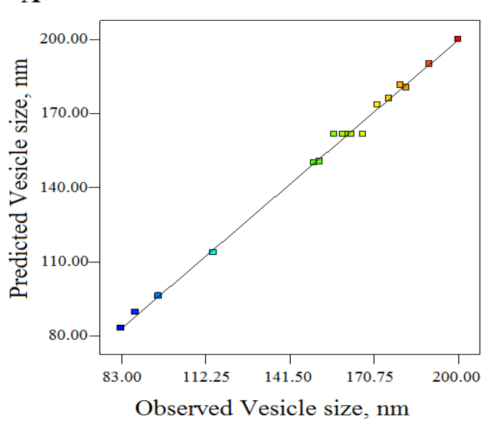

C

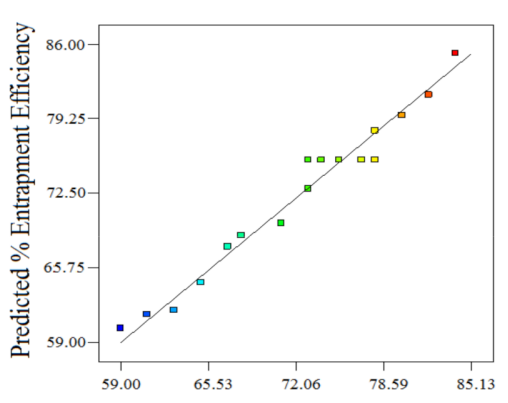

Observed \% Entrapment Efficiency

$\mathbf{E}$

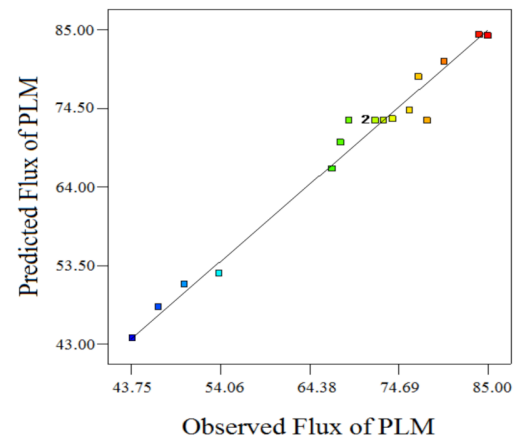

B

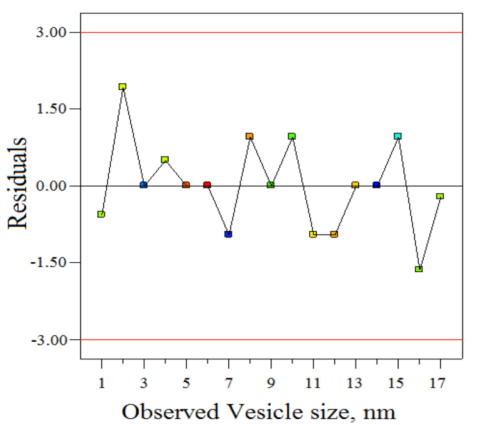

D

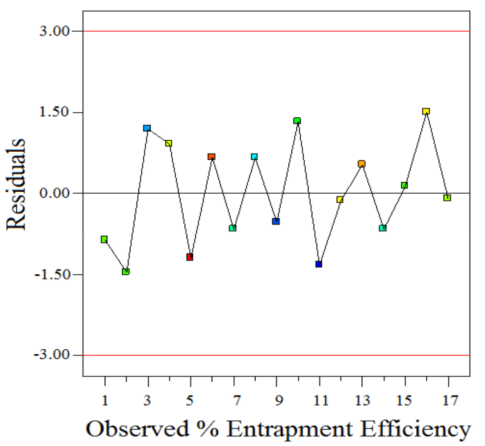

F

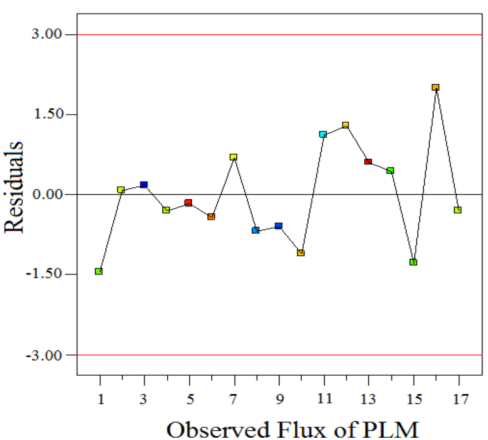

Figure 2. The linear correlation plots $(\mathbf{A}, \mathbf{C}, \mathbf{E})$ between predicted vs. observed values and corresponding residual plots $(\mathbf{B}, \mathbf{D}, \mathbf{F})$ for responses vesicle size, entrapment efficiency, and flux of plumbagin (PLM).

Table 3. Regression analysis summary for various responses $Y_{1}, Y_{2}$, and $Y_{3}$.

\begin{tabular}{|c|c|c|c|c|c|c|c|c|}
\hline Response Surface Quadratic Model & R-Squared & Adj R-Squared & Pred R-Squared & Adeq Precision & PRESS & $\% \mathrm{CV}$ & Mean & SD \\
\hline Response $1\left(\mathrm{y}_{1}\right)$ & 0.9966 & 0.9923 & 0.9851 & 48.695 & 302.25 & 2.05 & 152.47 & 3.13 \\
\hline Response $2\left(\mathrm{y}_{2}\right)$ & 0.9719 & 0.9358 & 0.8294 & 17.237 & 150.61 & 2.60 & 72.25 & 1.88 \\
\hline Response $3\left(\mathrm{y}_{3}\right)$ & 0.9767 & 0.9467 & 0.8689 & 18.105 & 334.87 & 4.24 & 68.82 & 2.92 \\
\hline \multicolumn{9}{|c|}{ Vesicle size $\left(Y_{1}\right)=161.60+46.25 \times X_{1}+12.25 \times X_{2}+0.75 \times X_{3}-3.00 \times X_{1} \times X_{2}+4.00 \times X_{1} \times X_{3}+0.50 \times X_{2} \times X_{3}-20.30 \times X_{1}^{2}+3.20 \times X_{2}^{2}-2.30 \times X_{3}^{2}$} \\
\hline \multicolumn{9}{|c|}{$\mathrm{EE}\left(\mathrm{Y}_{2}\right)=75.46+4.75 \times \mathrm{X}_{1}+2.13 \times \mathrm{X}_{2}+6.88 \times \mathrm{X}_{3}-0.50 \times \mathrm{X}_{1} \times \mathrm{X}_{2}+3.50 \times \mathrm{X}_{1} \times \mathrm{X}_{3}+2.75 \times \mathrm{X}_{2} \times \mathrm{X}_{3}+0.89 \times \mathrm{X}_{1}^{2}-1.36 \times \mathrm{X}_{2}^{2}-6.35 \times \mathrm{X}_{3}^{2}$} \\
\hline \multicolumn{9}{|c|}{ Flux $=72.80+4.63 \times X_{1}+2.50 \times X_{2}+15.63 \times X_{3}+0.75 \times X_{1} \times X_{2}+1.00 \times X_{1} \times X_{3}+0.25 \times X_{2} \times X_{3}-1.40 \times X_{1}^{2}+1.35 \times X_{2}^{2}-8.40 \times X_{3}^{2}$} \\
\hline
\end{tabular}

\subsubsection{Impact of Independent Variables on Vesicle Size $\left(\mathrm{Y}_{1}\right)$}

The impact of phospholipid concentration, cholesterol and glycerol concentration on vesicle size could be explicated by quadratic polynomial equation as shown in Table 3 . It was worth noting that the Model F-value of 360.55 implicated that the model was significant. 
The "Lack of Fit F-value" of 0.94 implies it was insignificant. The "Pred $R_{2}$ " of 0.99 is in reasonable agreement with the "Adj R2" of 0.99 as shown in Table 3.

The phospholipid concentration had significant positive impact on vesicles size of GMs $(p<0.05)$. The vesicles size analysis of developed formulation revealed the size ranges from $82.23 \pm 4.78 \mathrm{~nm}$ to $200 \pm 18.40 \mathrm{~nm}$. At low concentrations, the observed vesicle sizes were $82.23 \pm 4.78 \mathrm{~nm}$ and upon increasing the phospholid concentration to $22.5 \mathrm{mg}$, the maximum increase in vesicle size was $176 \pm 16.80 \mathrm{~nm}$ (FL13). Further increase in phospholipid concentration to $30 \mathrm{mg}$ led to maximum increase in vesicle size to $200.00 \pm 18.40 \mathrm{~nm}$ (FL6), as shown in Table 2. The result was observed similar of prior reported method [13].

The cholesterol concentration had positive impact on vesicles size of GMs. The increasing cholesterol concentration from 1.5 to $4.0 \% \mathrm{w} / \mathrm{v}$ led to an increase in vesicle size. Although, at same concentration of cholesterol, substantial decrease in vesicle size was observed as in FL14 formulation which could be due to combined effect of phospholipid and glycerol concentrations Table 2.

The glycerol concentration had less positive impact on the vesicle size. The formulation FL8 had vesicle size of $182 \pm 14.40 \mathrm{~nm}$ at $10 \% w / v$. Likewise, formulation FL9 and FL11 of same glycerol concentration $(10 \% w / v)$ had vesicle size of $150 \pm 12.70$ and $172 \pm 16.80 \mathrm{~nm}$, respectively. In spite of the aforementioned result, small vesicle size of $96 \pm 9.40 \mathrm{~nm}$ was observed in formulation FL3 at $10 \% w / v$ of glycerol concentration which could be due to combined impact of phospholipid and cholesterol concentrations. At $20 \% w / v$ of glycerol concentration FL1, FL2, FL4 and FL17 had vesicle size of $160 \pm 16.00 \mathrm{~nm}$, $167 \pm 17.10 \mathrm{~nm}, 163 \pm 15.20 \mathrm{~nm}$ and $161 \pm 13.50 \mathrm{~nm}$, respectively. Similar result was observed in formulation FL12 of vesicle size $180.3 \pm 15.40 \mathrm{~nm}$. Further, a substantial decrease in vesicle size was observed in FL14 at same concentration of glycerol which might be due to combining effect of phospholipid and cholesterol concentrations. The increasing aqueous glycerol concentration led to increased vesicle probably due to sticky texture of glycerol [27].

\subsubsection{Impact of Independent Variables on \% Entrapment Efficiency $\left(\mathrm{Y}_{2}\right)$}

The derived quadratic equation for \% entrapment efficiency (\%EE) as shown in Table 3. The Model F value of 26.93 implies that the model is significant. The "Lack of Fit F-value" of 0.64 implies it was insignificant. The "Pred $\mathrm{R}_{2}$ " of 0.82 was in reasonable agreement with the "Adj R2" of 0.93. The entrapment efficiency of optimized PLM-loaded GM formulation ranges in between $59 \pm 4.20 \%$ to $84 \pm 9.10 \%$. The increased phospholipid concentration led to increased \%EE of PLM-loaded GM due to signifcant positive impact $(p<0.05)$ on it as indicated in Table 2. The cholesterol concentration had positive impact on the \%EE. It was observed that increase in concentration of cholesterol from 1 to $2.5 \% w / v$ resulted enhanced entrapment of formulations as seen in Table 2. Moreover, at higher cholesterol concentration $(4 \% w / v)$ mixed effect was observed for formulations FL6, FL11, FL13 and FL15. The formulation FL6 and FL13 showed improved \%EE of $82 \pm 8.60 \%$ and $80 \pm 7.80 \%$, while FL15 and FL11 depicted decreased \%EE, i.e., $73 \pm 6.80 \%$ and $59 \pm 4.20 \%$, respectively. This is probably due to combined impact of different concentrations phospholipid, glycerol and cholesterol. The glycerol concentration had significant positive impact on EE $(p<0.05)$. It was observed that increasing glycerol concentration from $10 \%$ to $30 \% w / v$ increased the $\%$ EE from $59 \pm 4.20 \%$ to $84 \pm 9.10 \%$. However, in some formulations, FL7 and FL10 at $30 \%$ $w / v$ concentration of glycerol the $\% E E$ siginficantly dropped to $68 \pm 7.40 \%$ and $71 \pm 7.40 \%$ due to negative quadratic effect of glycerol $(p<0.05)$. All the obervations were reported in agreement with the previous studies [41].

\subsubsection{Impact of Independent Variables on Flux $\left(\mathrm{Y}_{3}\right)$}

The derived quadratic equation for flux is as shown in Table 3. The "Model F-value" of 32.59 suggested that the model is significant. The "Lack of Fit F-value" of 0.69 implies that the "Lack of Fit" is insignificant. The "Pred R2" of 0.86 was in reasonable agreement with 
the "Adj R2" of 0.94. The phospholipid concentration had siginficant positive impact on flux of PLM. It was ascertained that the flux of PLM steps up on increasing the phospholipid concentration from 15 to $30 \mathrm{mg}$ in the formulations. The PLM-loaded formulation with phsopholipid concentration range from 15 to $30 \mathrm{mg}$ had shown flux of $74 \pm 5.80 \mu \mathrm{g} / \mathrm{cm}^{2} / \mathrm{h}$ to $84 \pm 9.90 \mu \mathrm{g} / \mathrm{cm}^{2} / \mathrm{h}$, respectively.

The cholesterol concentration has low positive impact on the flux. At low cholesterol concentration $1.0 \% w / v$ the formulation FL10 expressed flux as $77.0 \pm 8.60 \mu \mathrm{g} / \mathrm{cm}^{2} / \mathrm{h}$ whereas further increasing cholesterol to $2.5 \% w / v$ the maximum increase in flux was observed in formulation FL5 as $84.0 \pm 9.90 \mu \mathrm{g} / \mathrm{cm}^{2} / \mathrm{h}$. It was examined that increasing the glycerol concentration leads to an increase in the flux due to significant positive impact of PLM flux $(p<0.05)$. At initial concentration of glycerol $(10 \% w / v)$ the flux of PLM for formulation FL3 was $44.0 \pm 4.30 \mu \mathrm{g} / \mathrm{cm}^{2} / \mathrm{h}$ and further increasing the glycerol concentration from 20 to $30 \% w / v$, the flux increases from $67.0 \pm 6.70 \mu \mathrm{g} / \mathrm{cm}^{2} / \mathrm{h}$ in formulation (FL14) to $85.0 \pm 9.90 \mu \mathrm{g} / \mathrm{cm}^{2} / \mathrm{h}$ (FL13).

The optimized formuation of GMs comprised of phospholipid concentration, (15 mg), cholesterol concentration $(4.00 \mathrm{mg})$ and glycerol $(26.8 \% \mathrm{w} / \mathrm{v})$. The design expert software revealed the predicted values of dependent variables, i.e., vesicle size, entrapment efficiency and flux of PLM was $110.53 \mathrm{~nm}, 74.09 \%$ and $76.12 \mu \mathrm{g} / \mathrm{cm}^{2} / \mathrm{h}$, respectively. Further, the selected optimized formulation experimentally performed and evaluated for vesicle size, entrapment efficiency and flux were found to be $119.20 \pm 15.67 \mathrm{~nm}, 76.42 \pm 9.98 \%$ and $79.43 \pm 12.43 \mu \mathrm{g} / \mathrm{cm}^{2} / \mathrm{h}$. The percentage error reported between observed vs. predicted values of vesicle size, entrapment efficiency and flux were 8.18, 3.14, and 4.34 within the acceptable range (Table 4). It was noticed that the experimental values were established closer to the predicted values established by design expert software. The vesicle appeared marginally bigger than predicted vesicle size by design expert reasonably due to lyophilized state of formulation. In addition, the PDI and zeta potential value of optimized formulation was found to be $0.145 \pm 0.02$, zeta potential $-27 \pm 5.12 \mathrm{mV}$. The low value of PDI substantiated narrow size distribution, consistent and homogeneous nature of formulation [42]. The surface negative charge shown by zeta potential studies over optimized formulation clarified it exits over the surface of vesicle which may be contributed to by cholesterol or glycerol used in the formulation. The negative charge over vesicle surface further assured the de-aggregation of vesicles due to electrostatic repulsion and that resistive force may facilitate in enhancing the bio-stability of nanovesicles [43].

Table 4. Composition, experimental vs. predicted value with percentage error of optimized PLMloaded glycerosome formulation.

\begin{tabular}{cccccc}
\hline Variables & $\begin{array}{c}\text { Optimum } \\
\text { Composition }\end{array}$ & Response & $\begin{array}{c}\text { Observed Value } \\
\text { of Response }\end{array}$ & $\begin{array}{c}\text { Predicted Value } \\
\text { of Response }\end{array}$ & $\begin{array}{c}\text { Percentage } \\
\text { Error }\end{array}$ \\
\hline $\mathrm{X}_{1}$ & $15 \mathrm{mg}$ & $\mathrm{Y}_{1}$ & $119.20 \pm 15.67$ & 110.53 & 8.18 \\
\hline $\mathrm{X}_{2}$ & $4 \mathrm{mg}$ & $\mathrm{Y}_{2}$ & $76.42 \pm 9.98$ & 74.09 & 3.14 \\
\hline $\mathrm{X}_{3}$ & $26.8 \% w / v$ & $\mathrm{Y}_{3}$ & $79.43 \pm 12.43$ & 76.12 & 4.34 \\
\hline
\end{tabular}

Predicted error $(\%)=($ observed value - predicted value $) /$ predicted value $\times 100 \% ; \mathrm{X}_{1}$, Phospholipid (mg); $\mathrm{X}_{2}$ Cholesterol ( $\% v / v) ; X_{3}$, Glycerol, $\mathrm{Y}_{1}$, Vesicles size (nm); $\mathrm{Y}_{2}$, Entrapment efficiency; $\mathrm{Y}_{3}$, Drug permeation/Flux $\left(\mu \mathrm{g} / \mathrm{cm}^{2} / \mathrm{h}\right)$.

\subsection{Characterization of Nanosystems Dispersion}

\subsubsection{Particle Size, Zeta Potential, Morphology, Entrapment and Drug Loading Efficiency}

A mean vesicle size of $119.20 \pm 15.67 \mathrm{~nm}$ with uniform size distribution and PDI value of $0.145 \pm 0.02$ (Figure $3 \mathrm{~A}$ ) was optimized for the developed glycerosomal formulation. The vesicle surface was negative since the zeta potential value was analysed to be $-27 \pm 5.12 \mathrm{mV}$ as shown in Figure 3B. The TEM image of GMs indicated that the particles were uniform in size, consistent, spherical and homogenously dispersed as depicted in Figure 3C. The observed entrapment efficiency and drug loading for optimized PLM-loaded GMs were $76.42 \pm 9.98$ and $7.64 \pm 1.12 \%$, respectively. The in vitro characteri- 
zation of PLM-loaded CLs in terms of size, PDI, surface charge, entrapment, drug loading efficiency and transmission electron micrograph are provided in (Supplementary Sheet Table S1 \& Figure S1).
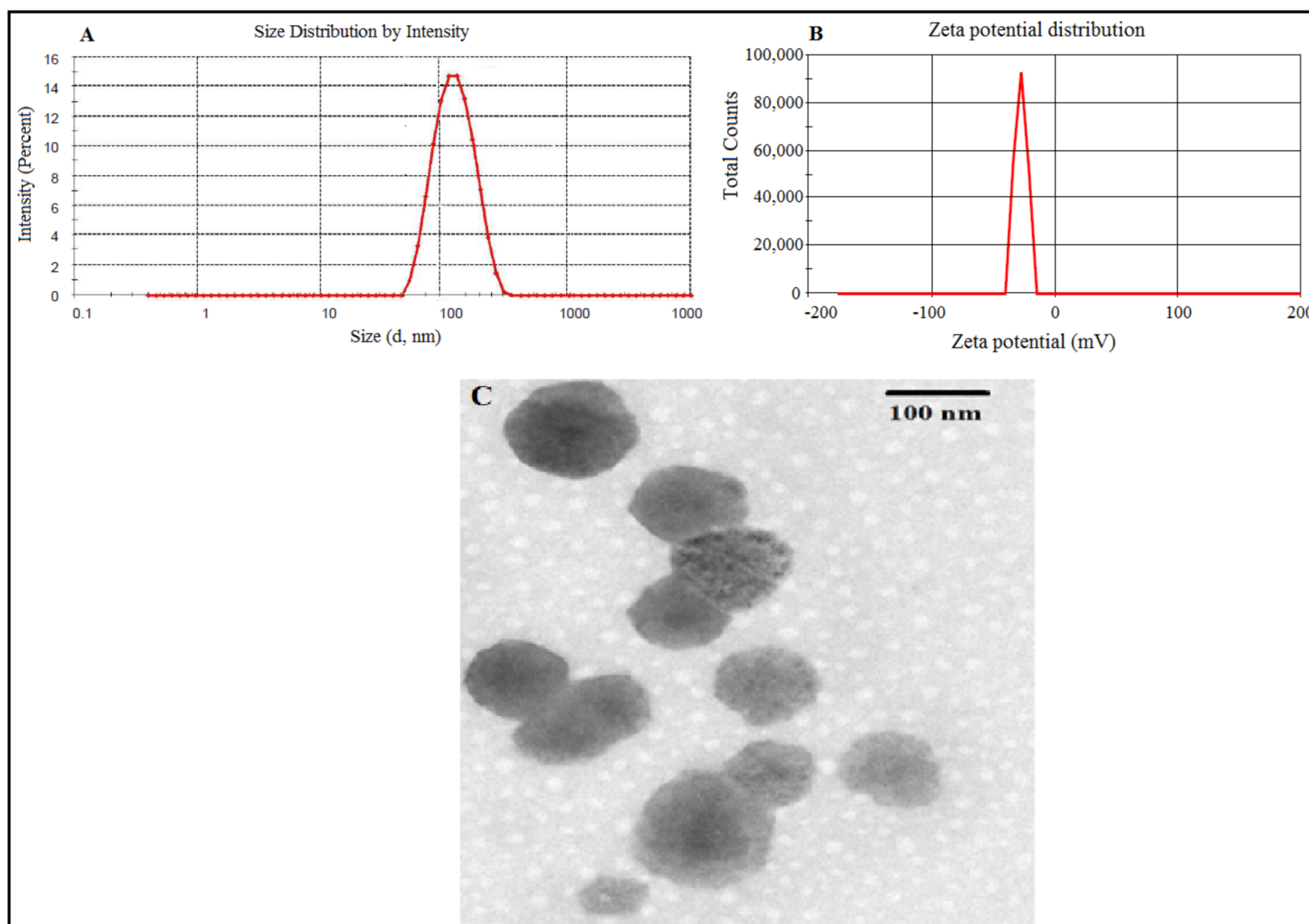

Figure 3. Optimized PLM-loaded glycerosomes (A) average vesicle size (B) zeta potential and (C) transmission electron micrograph.

\subsubsection{In Vitro Drug Release and Kinetic Study}

The release profiles of PLM-loaded GMs, CLs and PLM suspension in PBS (pH 4.5, 7.4) is expressed in Figure 4A,B. The release study was conducted for $12 \mathrm{~h}$ and it was observed that PLM release pattern from GM was biphasic, i.e., initial burst release accompanied with sustained release pattern. In the first hour, release of PLM from PLM-loaded GMs, CLs and PLM suspension at $\mathrm{pH} 4.5$ were found to be $51.5 \pm 5.0 \%, 23.6 \pm 4.0 \%$ and $3.1 \pm 1.0 \%$, respectively. On the other hand, the PLM release from PLM-loaded GM, CL and PLM suspension at pH 7.4 for first hour were found to be $40 \pm 3.6 \%, 21.5 \pm 4.0 \%$ and $3.6 \pm 0.4 \%$, respectively. The result has shown significant differences $(p<0.05)$ in the drug release profile of PLM-loaded GM at pH 4.5 and 7.4 for first hour. The PLM released from PLMloaded GMs, CLs and PLM suspension at $12 \mathrm{~h}$ were observed to be $88.5 \pm 5.5 \%, 67.4 \pm 7.5 \%$ and $20.4 \pm 6.5 \%$, respectively. Further, drug release at $\mathrm{pH}$ 7.4 from PLM-loaded GM, CL and PLM suspension were $82.6 \pm 7.0 \%, 62.3 \pm 7.5 \%$ and $18.3 \pm 8.0 \%$. The result has shown small increase in drug release at acidic $\mathrm{pH}$ as compared to $\mathrm{pH}$ 7.4. However, the result has shown no significant differences $(p>0.05)$ in the drug release profile of all formulations at pH 4.5 and 7.4 over $12 \mathrm{~h}$. The release of PLM from GM and CL was more at acidic $\mathrm{pH} 4.5$ than at $\mathrm{pH} 7.4$ probably due to enhanced solubility of aggregated drugs inside vesicles. However, the significant differences $(p<0.05)$ were observed in percent release of PLM from GM as compared to CL and PLM suspension over $12 \mathrm{~h}$ at $\mathrm{pH} 4.5$ and 7.4. The 
obtained dissolution profile of PLM was comparable to earlier cited work based on the transferrin conjugated PLM liposome [44]. The drug release profile was fitted into various release kinetic models (Zero order, first order, Higuchi, and Hixon Crowell) to screen out the best fitted model as shown in Table S2. Based on R2 value, the best fitted model for PLM-loaded GMs was Higuchi model with R2 value of 0.9758 [32]. The release mechanism of PLM-loaded GMs was analyzed by applying Korsmeyer-Pappas model and the value of $\mathrm{n}$ exponent was found 0.69, i.e., in between 0.5 to 0.89 which represent that PLM released follow non-fickian diffusion mechanism [45].
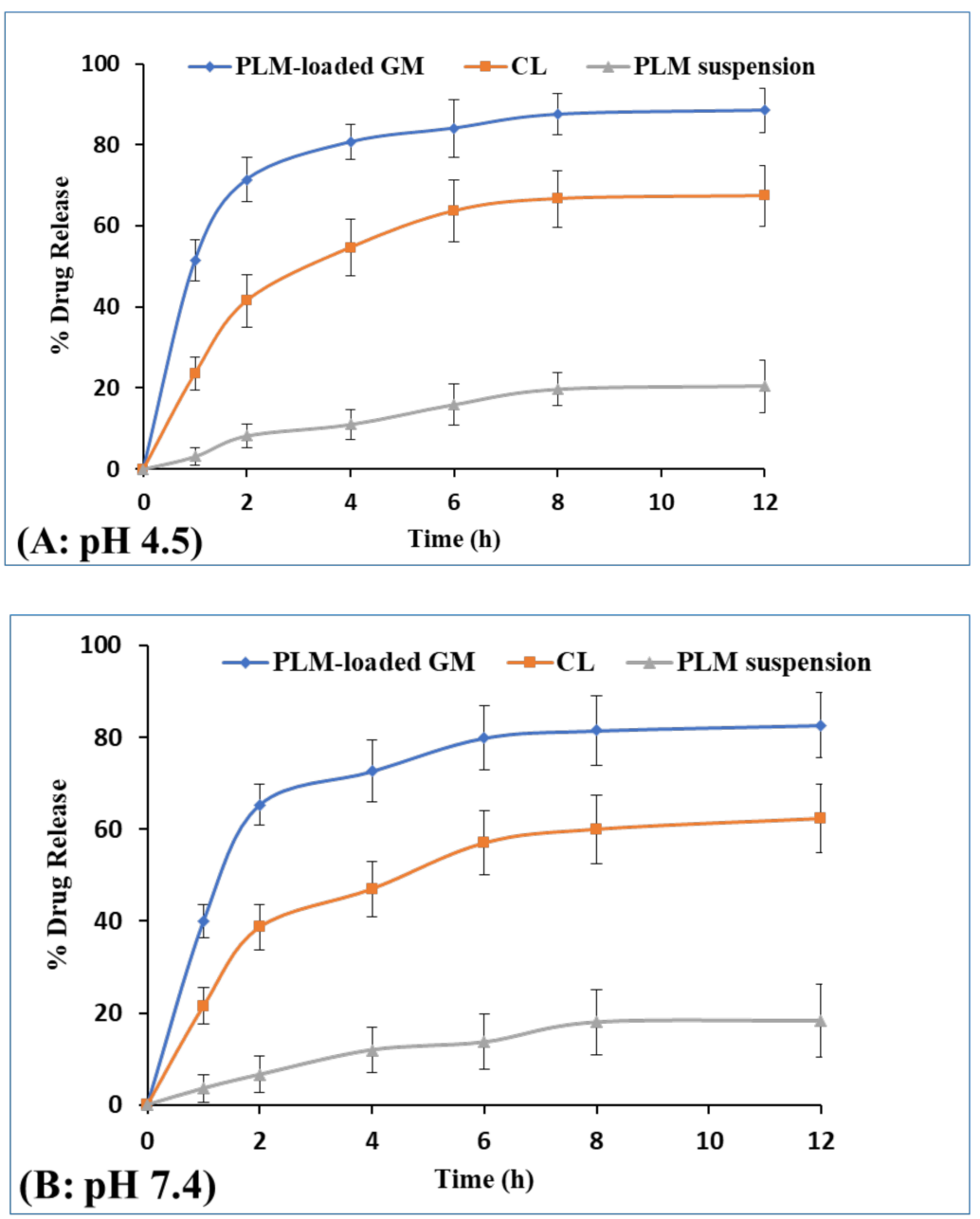

Figure 4. Percent drug release of PLM from PLM-loaded glycerosomes, CLs and PLM suspension in PBS of pH 4.5 (A) and 7.4 (B), respectively.

\subsubsection{Characterization of Gels}

The prepared GM-loaded gels were good in consistency, appearance, as well as texture. The $\mathrm{pH}$ value of developed formulation was tested and was found to be $7.40 \pm 0.03$ which was within the acceptable range, hence free from any form of irritancy [33]. The texture analysis of prepared gel was subjected to force curve plot. The results obtained after analysis of GM-loaded gels formulation expressed as firmness or hardness value, viscosity index, consistency and cohesiveness were found to be $212.70 \mathrm{~g}, 221$ g.s, 63.54 g.s and $-151.60 \mathrm{~g}$, respectively. On the other hand, for CL gel firmness or hardness value, viscosity index, consistency and cohesiveness were found to be $219.30 \mathrm{~g}, 230.32$ g.s, 39.08 g.s and $-160.72 \mathrm{~g}$, respectively. The spreadability of CL gels and GM-loaded gels were measured and $1.34 \pm 0.16 \mathrm{~cm}$ and $2.74 \pm 0.28 \mathrm{~cm}$, respectively. Therefore, texture testing of the developed GM-loaded gel is substantially accommodated for topical application because of its good consistency, cohesiveness, firmness, and viscosity compared to CL gel [13]. 


\subsubsection{Skin Permeation Study}

The skin permeation and penetration ability of drug from GM-loaded gel was carried out using animal skin as shown in Figure 5A. The flux was determined over a period of $24 \mathrm{~h}$ and calculated from slope of linear part of the graph. The maximum flux at end point of the study from GM-loaded gels, CL gels and PLM suspension were $79.43 \pm 12.43,23.31 \pm 6.0$, and $12.3 \pm 4.5 \mu \mathrm{g} / \mathrm{cm}^{2} / \mathrm{h}$. The outcome of the study ascertained that flux of PLM from GM-loaded gels was statistically significant when compared with flux of PLM from CL gel $(p=0.0159)$ and PLM suspension $(p=0.0006)$. The high degree of permeation from the glycerosomal gel clearly indicated the presence of glycerol in the vehicle which makes the vesicle ultra-deformable and elastic in nature thereby allowing the drug to penetrate deeper to cutaneous layer and dermal tissues. Poor drug solubility, permeation as well as cutaneous barrier through the strata of skin are some of the possible reasons for obtaining low flux from PLM suspension.
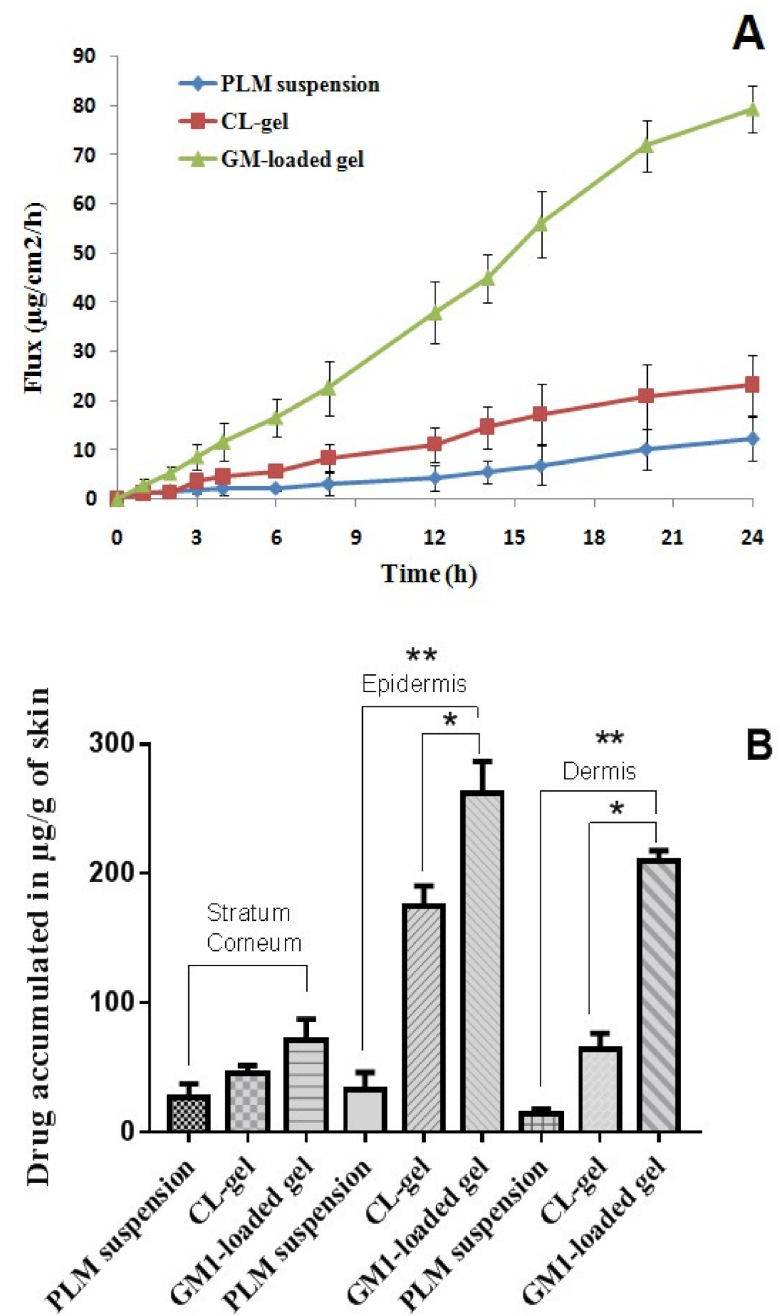

B

Figure 5. (A) Represents skin permeation studies in which flux of PLM suspension, CL gel and GM-loaded gel were compared and (B) The amount of drug retained in stratum corneum, epidermis and dermis from free PLM, CL gel, and GM-loaded gel, respectively. Data expressed as mean \pm SD $\left.(n=3){ }^{*} p \leq 0.05,{ }^{* *} p \leq 0.01\right)$.

\subsubsection{Drug Retention Study}

The amount of drug retained in the stratum corneum, epidermis, and dermis were analyzed by HPLC and expressed in $\mu \mathrm{g} / \mathrm{g}$ of skin tissues. The amount of PLM from suspension, PLM from CL gels and GM-loaded gels deposited in the SC were 37, 50.8 and $89 \mu \mathrm{g} / \mathrm{g}$ of skin tissue. Further, the amount of PLM from suspension, CL gels and 
GM-loaded gels deposited in the epidermis were $45,188.4$ and $289 \mu \mathrm{g} / \mathrm{g}$ of skin. Moreover, the dermis had 17, 73.98 and $210 \mu \mathrm{g} / \mathrm{g}$ of skin tissue of PLM from suspension, CL gels and GM-loaded gels as shown in Figure 5B. In comparison to drug suspension and CL gels, significant amount of PLM was deposited in the epidermis and dermis from GM-loaded gels $(p<0.05)$ which was probably due to edge activating effect and ultra-deformable and elastic behavior of GM containing glycerol.

\subsubsection{Confocal Laser Microscopy}

The depth of penetration from both Rhodamine B solution and Rhodamine B encapsulated GMs were compared. The microscopy revealed that the maximum depth of penetration from Rhodamine B solution was $12.45 \mu \mathrm{m}$ while Rhodamine B encapsulated GM formulation reached upto $173.56 \mu \mathrm{m}$ deeper in the soft tissues of skin as indicated in Figure 6. The high degree of penetration from Rhodamine B encapsulated GM was probably owing to fusion of vesicle content with different layers of skin, followed by disruption of vesicle and enhanced fluidity of lipidic layer that led to eventual distribution of Rhodamine B. In fact, the glycerol was able to modify the fluidity of lipid bilayer in the vesicle and easily squeezed through microscopic pores into the deeper soft layers of skin [46].
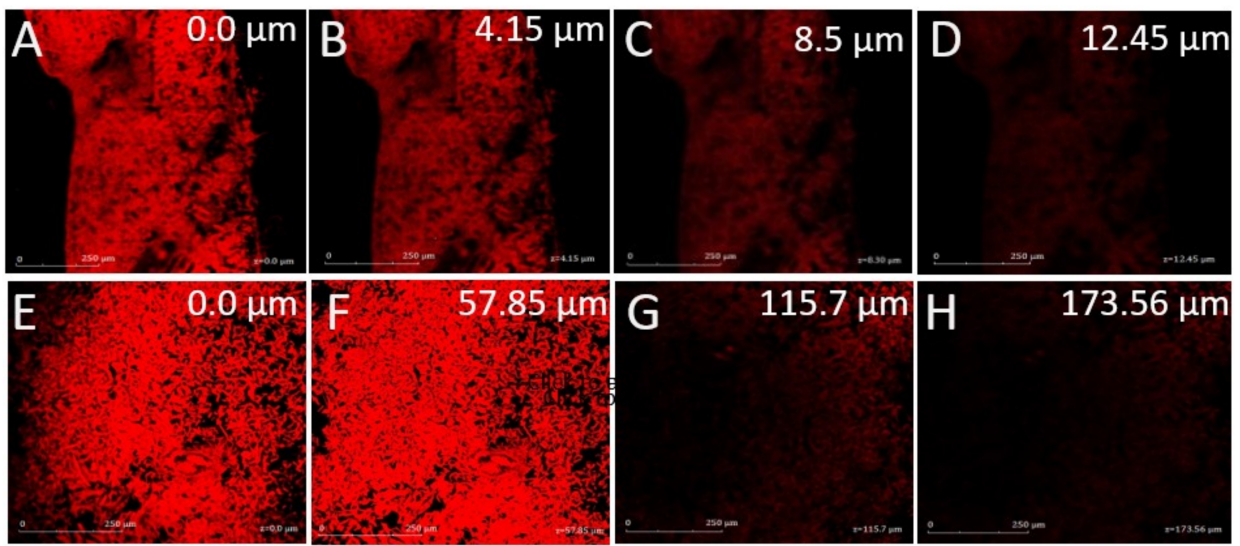

Figure 6. Confocal laser microscopy of (A-D) Rhodamine B solution and (E-H) Rhodamine B-loaded glycerosome, scale bar $=250 \mu \mathrm{m}$.

\subsubsection{MTT Assay}

The cytotoxic assessment was performed via MTT assay on murine tumor cell line (B16-F10) for human skin cancer. As per the assay, the cell viability (\%) after treatment with PLM suspension, CL gels and GM-loaded gels was obtained. The outcomes of the MTT assay demonstrated that GM-loaded gels showed significantly enhanced cytotoxicity when compared to PLM suspension and CL gels Figure 7A-C. It was observed that cytotoxic assessment was concentration and time dependent because as the concentration and time of exposure increased, better apoptosis of cells took place. Blank formulation of GMs and CLs did not show any sign of cytotoxicity. The $\mathrm{IC}_{50}$ values of PLM suspension, CLs and GM-loaded gels are as shown in Table 5. The outcomes evidently show that GM-loaded gel had significantly higher cytotoxic effect than CL and PLM suspension $(p<0.05)$ over different periods of incubation. The high concentration of PLM was passively transported to inside the cells thus leading to cytotoxic effect. Further, the nanovehicle releases drug intracellularly through various transporters in the extracellular matrix present on the cell membrane [47]. 

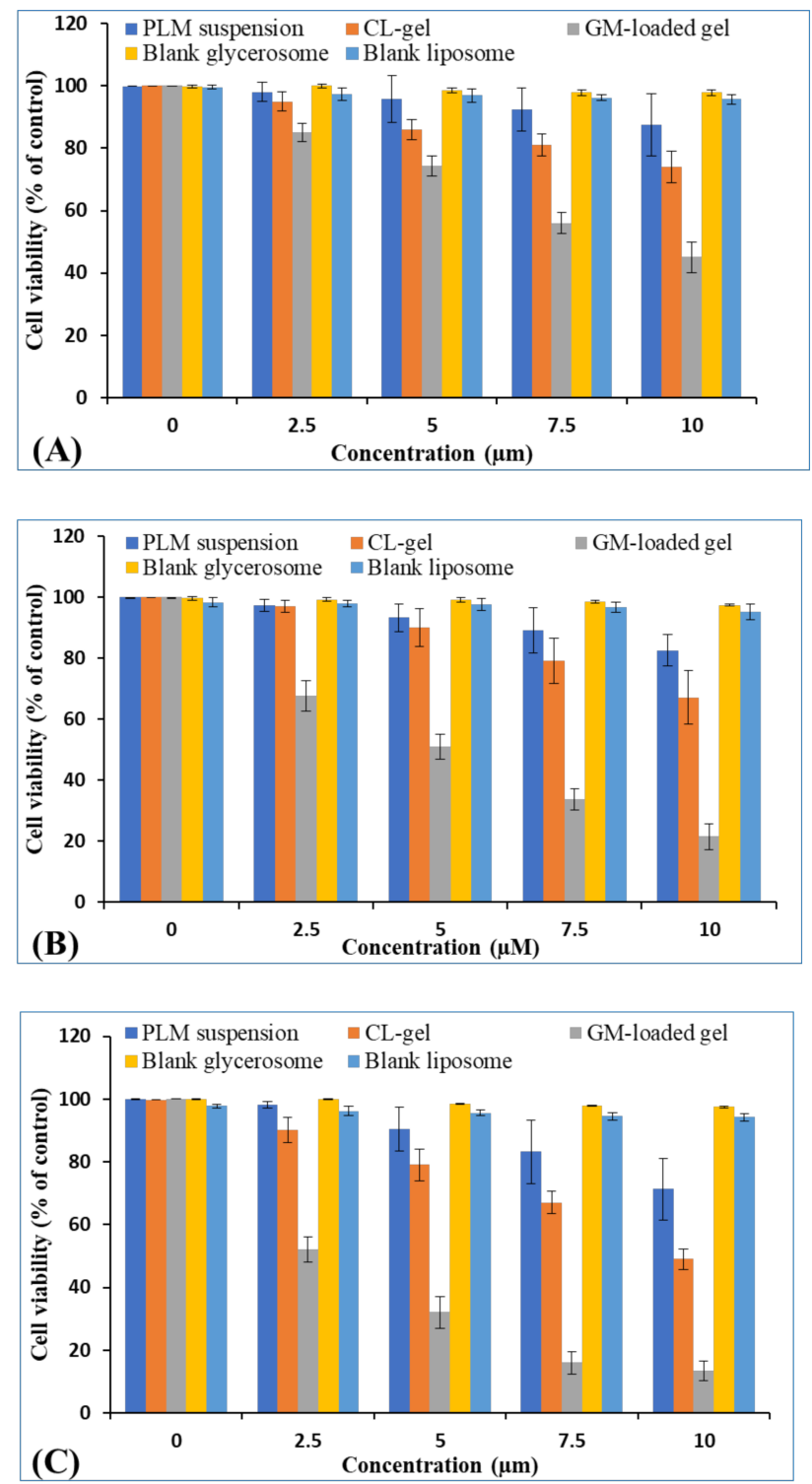

Figure 7. The cell viability of PLM suspension, CL and GM-loaded gel, blank GM and blank liposome post $24 \mathrm{~h} \mathrm{(A)} 48 \mathrm{~h} \mathrm{(B)}$ and $72 \mathrm{~h}(\mathbf{C})$ in cancer cell line. Data expressed as mean $\pm \operatorname{SD}(n=3)$.

Table 5. $\mathrm{IC}_{50}$ value of PLM suspension, CL gel and GM-loaded gel containing PLM in B16-F10 cell line.

\begin{tabular}{cccc}
\hline Incubation Time (h) & PLM Suspension $(\boldsymbol{\mu m})$ & CL Gel $(\mu \mathrm{m})$ & GM-Loaded Gel $(\boldsymbol{\mu m})$ \\
\hline 24 & $41.7 \pm 2.3$ & $19.0 \pm 1.2$ & $8.9 \pm 0.6$ \\
\hline 48 & $29.8 \pm 1.4$ & $16.0 \pm 1.3$ & $5.6 \pm 0.4$ \\
\hline 72 & $19.1 \pm 1.7$ & $10.4 \pm 0.8$ & $4.1 \pm 0.3$ \\
\hline
\end{tabular}

\subsubsection{Antioxidant Activity}

The antioxidant activity was evaluated using DPPH assays. The estimation of Trolox equivalent antioxidant capacity (TEAC) was performed from the standard curve of Trolox. The TEAC value of optimized GM-loaded gels was 17, 25, 39, 66, and $80 \mu \mathrm{g}$ trolox equivalent per 10, 20, 50, 100, and $150 \mu \mathrm{g} / \mathrm{mL}$ of trolox in DPPH assay (Figure 8). The GM-loaded gels showed significantly higher antioxidant activity than PLM suspension $(p<0.05)$ [48]. 

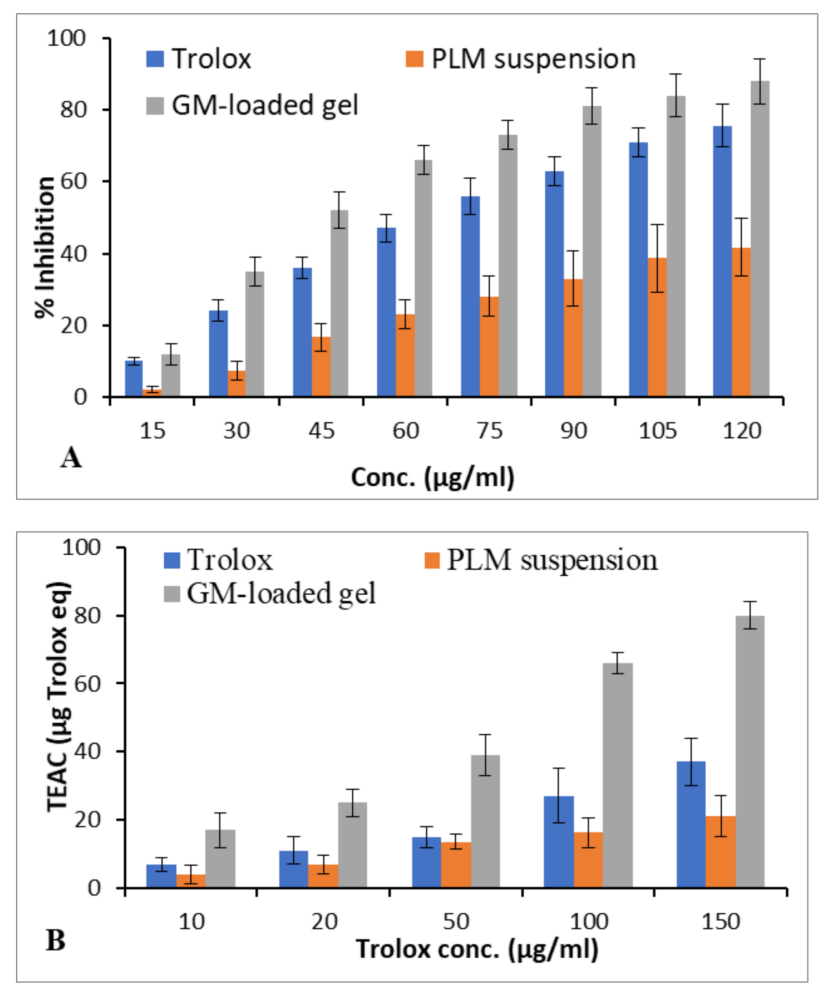

Figure 8. The antioxidant activities govern by DPPH assay of PLM suspension and GM-loaded gel. Percentage inhibitory effect of antioxidant (A). Trolex equivalent antioxidant activity (TEAC) of GM-loaded gel compared with trolox and PLM suspension (B). Values shown as means \pm SD $(n=3)$ analysed by one way ANOVA followed by Bartlett's test for statistical significance $(p<0.05)$.

\section{Conclusions}

The novel formulation of GM-loaded gels was successfully developed and compared with CLs formulation and PLM suspension. The GM formulation was optimized using Box-Behnken statistical design and successfully studied the effects of independent variableson dependent variables. The optimized formulation was expressed as nano-size vesicle, negatively charged ZP and high entrapment efficiency. The developed formulation exhibited sustained release and gave excellent flux across various strata of cutaneous layer. The confocal laser microscopy revealed considerably good and deep penetration of GM inside the cutaneous layers. Cytotoxic assessment of GM-loaded gels showed significant cytotoxicity over CL and PLM suspension. The antioxidant study of PLM from GM-loaded gels demonstrated pronounced antioxidant effect as compared to CL and PLM suspension. Overall, the study proved that PLM containing GM-loaded gels could be a promising carrier in skin cancer therapy.

Supplementary Materials: The following are available online at https://www.mdpi.com/2073-4 360/13/6/923/s1, Table S1. The particle size, PDI, zeta potential, entrapment efficiency and drug loading of PLM-loaded glycerosome, PLM-loaded CL and rhodamine-loaded glycerosome; Figure S1. Diagram showing (A) Average size of vesicle $129.56 \pm 17.05 \mathrm{~nm}$; PI $0.245 \pm 0.032$, (B) zeta potential $-22.50 \pm 5.61(\mathrm{mV})$, and (C) Transmission electron micrograph of optimized PLM-loaded liposome formulation; Table S2. Drug release kinetic analysis of optimized PLM-loaded GM formulation.

Author Contributions: Conceptualization, Conceptualization, S.M., H.M.A., M.H. and M.A.A.; Data curation, N.A.A., M.H. and M.H.A.; Formal analysis, N.A.A., M.H., N.K., Y.R. and M.H.A.; Funding acquisition, S.M., H.M.A. and M.A.A.; Methodology, S.M., N.A.A., H.M.A., M.A.A., H.Z.A. and A.L.B.; Supervision, H.Z.A.; Writing-original draft, N.K. and M.H.A.; Writing-review and editing, H.Z.A., Y.R. and A.L.B. All authors have read and agreed to the published version of the manuscript. 
Funding: This project was funded by the Deanship of Scientific Research (DSR) at King Abdulaziz University, Jeddah, under grant no. (RG-12-166-38).

Acknowledgments: The authors, therefore, acknowledge with thanks DSR for technical and financial support.

Conflicts of Interest: The authors declare no conflict of interest.

\section{References}

1. Bray, F.; Ferlay, J.; Soerjomataram, I.; Siegel, R.L.; Torre, L.A.; Jemal, A. Global cancer statistics 2018: GLOBOCAN estimates of incidence and mortality worldwide for 36 cancers in 185 countries. CA Cancer J. Clin. 2018, 68, 394-424. [CrossRef]

2. Priya, P.; Raj, R.M.; Vasanthakumar, V.; Raj, V. Curcumin-loaded layer-by-layer folic acid and casein coated carboxymethyl cellulose/casein nanogels for treatment of skin cancer. Arab. J. Chem. 2020, 13, 694-708. [CrossRef]

3. Akhter, H.; Amin, S. An Investigative Approach to Treatment Modalities for Squamous Cell Carcinoma of Skin. Curr. Drug Deliv. 2017, 14, 597-612. [CrossRef]

4. Akhter, H.; Ahsan, M.J.; Rahman, M.; Anwar, S. Rizwanullah Advancement in Nanotheranostics for Effective Skin Cancer Therapy: State of the Art. Curr. Nanomed. 2020, 10, 90-104. [CrossRef]

5. Soni, K.; Mujtaba, A.; Akhter, H.; Zafar, A.; Kohli, K. Optimisation of ethosomal nanogel for topical nano-CUR and sulphoraphane delivery in effective skin cancer therapy. J. Microencapsul. 2019, 37, 91-108. [CrossRef] [PubMed]

6. Oberli, M.A.; Schoellhammer, C.M.; Langer, R.; Blankschtein, D. Ultrasound-enhanced transdermal delivery: Recent advances and future challenges. Ther. Deliv. 2014, 5, 843-857. [CrossRef] [PubMed]

7. Rawat, S.; Vengurlekar, S.; Rakesh, B.; Jain, S.; Srikarti, G. Transdermal delivery by iontophoresis. Indian J. Pharm. Sci. 2008, 70, 5-10. [CrossRef] [PubMed]

8. Daftardar, S.; Neupane, R.; Boddu, S.H.; Renukuntla, J.; Tiwari, A.K. Advances in Ultrasound Mediated Transdermal Drug Delivery. Curr. Pharm. Des. 2019, 25, 413-423. [CrossRef] [PubMed]

9. Sarheed, O.; Shouqair, D.; Ramesh, K.; Khaleel, T.; Amin, M.; Boateng, J.; Drechsler, M. Formation of stable nanoemulsions by ultrasound-assisted two-step emulsification process for topical drug delivery: Effect of oil phase composition and surfactant concentration and loratadine as ripening inhibitor. Int. J. Pharm. 2020, 576, 118952. [CrossRef]

10. Song, Y.-Y.; Yuan, Y.; Shi, X.; Che, Y.-Y. Improved drug delivery and anti-tumor efficacy of combinatorial liposomal formulation of genistein and plumbagin by targeting Glut1 and Akt3 proteins in mice bearing prostate tumor. Colloids Surf. B Biointerfaces 2020, 190, 110966. [CrossRef] [PubMed]

11. Akhter, H.; Rizwanullah, M.; Ahmad, J.; Ahsan, M.J.; Mujtaba, A.; Amin, S. Nanocarriers in advanced drug targeting: Setting novel paradigm in cancer therapeutics. Artif. Cells, Nanomed. Biotechnol. 2018, 46, 873-884. [CrossRef]

12. Maheshwari, R.G.; Tekade, R.K.; Sharma, P.A.; Darwhekar, G.; Tyagi, A.; Patel, R.P.; Jain, D.K. Ethosomes and ultradeformable liposomes for transdermal delivery of clotrimazole: A comparative assessment. Saudi Pharm. J. 2012, 20, 161-170. [CrossRef]

13. Kausar, H.; Mujeeb, M.; Ahad, A.; Moolakkadath, T.; Aqil, M.; Ahmad, A.; Akhter, H. Optimization of ethosomes for topical thymoquinone delivery for the treatment of skin acne. J. Drug Deliv. Sci. Technol. 2019, 49, 177-187. [CrossRef]

14. Verma, P.; Pathak, K. Therapeutic and cosmeceutical potential of ethosomes: An overview. J. Adv. Pharm. Technol. Res. 2010, 1, 274-282. [CrossRef]

15. Jain, S.; Tiwary, A.K.; Sapra, B.; Jain, N.K. Formulation and evaluation of ethosomes for transdermal delivery of lamivudine. AAPS PharmSciTech 2007, 8, 249-257. [CrossRef] [PubMed]

16. Zaru, M.; Manca, M.L.; Fadda, A.M.; Orsini, G. Glycerosomes and Use Thereof in Pharmaceutical and Cosmetic Preparations for Topical Applications. U.S. Patent No. 8,778,367, 5 July 2014.

17. Kaminski, G.A.; Sierakowski, M.R.; Pontarolo, R.; Dos Santos, L.A.; De Freitas, R.A. Layer-by-layer polysaccharide-coated liposomes for sustained delivery of epidermal growth factor. Carbohydr. Polym. 2016, 140, 129-135. [CrossRef]

18. Ahmad, J.; Ameeduzzafar; Ahmad, M.Z.; Akhter, H. Surface-Engineered Cancer Nanomedicine: Rational Design and Recent Progress. Curr. Pharm. Des. 2020, 26, 1181-1190. [CrossRef]

19. Kaewbumrung, S.; Panichayupakaranant, P. Antibacterial activity of plumbagin derivative-rich Plumbago indica root extracts and chemical stability. Nat. Prod. Res. 2014, 28, 835-837. [CrossRef] [PubMed]

20. Tripathi, S.K.; Panda, M.; Biswal, B.K. Emerging role of plumbagin: Cytotoxic potential and pharmaceutical relevance towards cancer therapy. Food Chem. Toxicol. 2019, 125, 566-582. [CrossRef] [PubMed]

21. Li, T.; Lv, M.; Chen, X.; Yu, Y.; Zang, G.; Tang, Z. Plumbagin inhibits proliferation and induces apoptosis of hepatocellular carcinoma by downregulating the expression of SIVA. Drug Des. Dev. Ther. 2019, 13, 1289-1300. [CrossRef]

22. Gomathinayagam, R.; Sowmyalakshmi, S.; Mardhatillah, F.; Kumar, R.; Akbarsha, M.A.; Damodaran, C. Anticancer mechanism of plumbagin, a natural compound, on non-small cell lung cancer cells. Anticancer. Res. 2008, 28, 785-792.

23. Sand, J.M.; Bin Hafeez, B.; Jamal, M.S.; Witkowsky, O.; Siebers, E.M.; Fischer, J.; Verma, A.K. Plumbagin (5-hydroxy-2-methyl1,4-naphthoquinone), isolated from Plumbago zeylanica, inhibits ultraviolet radiation-induced development of squamous cell carcinomas. Carcinog. 2011, 33, 184-190. [CrossRef] [PubMed] 
24. Jamal, M.S.; Parveen, S.; Beg, M.A.; Suhail, M.; Chaudhary, A.G.A.; Damanhouri, G.A.; Abuzenadah, A.M.; Rehan, M. Anticancer Compound Plumbagin and Its Molecular Targets: A Structural Insight into the Inhibitory Mechanisms Using Computational Approaches. PLoS ONE 2014, 9, e87309. [CrossRef]

25. Kortylewski, M.; Jove, R.; Yu, H. Targeting STAT3 affects melanoma on multiple fronts. Cancer Metastasis Rev. 2005, $24,315-327$. [CrossRef]

26. Oh, T.-I.; Yun, J.-M.; Park, E.-J.; Kim, Y.-S.; Lee, Y.-M.; Lim, J.-H. Plumbagin Suppresses $\alpha$-MSH-Induced Melanogenesis in B16F10 Mouse Melanoma Cells by Inhibiting Tyrosinase Activity. Int. J. Mol. Sci. 2017, 18, 320. [CrossRef] [PubMed]

27. Manca, M.L.; Zaru, M.; Manconi, M.; Lai, F.; Valenti, D.; Sinico, C.; Fadda, A.M. Glycerosomes: A new tool for effective dermal and transdermal drug delivery. Int. J. Pharm. 2013, 455, 66-74. [CrossRef]

28. Gupta, P.; Mazumder, R.; Padhi, S. Glycerosomes: Advanced Liposomal Drug Delivery System. Indian J. Pharm. Sci. 2020, 82, 385-397. [CrossRef]

29. Lombardo, D.; Calandra, P.; Barreca, D.; Magazù, S.; Kiselev, M.A. Soft Interaction in Liposome Nanocarriers for Therapeutic Drug Delivery. Nanomater. 2016, 6, 125. [CrossRef]

30. Zhang, H. Thin-Film Hydration Followed by Extrusion Method for Liposome Preparation. NMR-Based Metab. 2017, 1522, 17-22. [CrossRef]

31. Ahad, A.; Aqil, M.; Kohli, K.; Sultana, Y.; Mujeeb, M. Design, formulation and optimization of valsartan transdermal gel containing iso-eucalyptol as novel permeation enhancer: Preclinical assessment of pharmacokinetics in Wistar albino rats. Expert Opin. Drug Deliv. 2014, 11, 1149-1162. [CrossRef]

32. Akhter, H.; Kumar, S.; Nomani, S. Sonication tailored enhance cytotoxicity of naringenin nanoparticle in pancreatic cancer: Design, optimization, and in vitro studies. Drug Dev. Ind. Pharm. 2020, 46, 659-672. [CrossRef] [PubMed]

33. Ahad, A.; Al-Saleh, A.A.; Al-Mohizea, A.M.; Al-Jenoobi, F.I.; Raish, M.; Yassin, A.E.B.; Alam, M.A. Pharmacodynamic study of eprosartan mesylate-loaded transfersomes Carbopol ${ }^{\circledR}$ gel under Dermaroller ${ }^{\circledR}$ on rats with methyl prednisolone acetate-induced hypertension. Biomed. Pharmacother. 2017, 89, 177-184. [CrossRef]

34. Ahad, A.; Raish, M.; Al-Jenoobi, F.I.; Al-Mohizea, A.M. Sorbitane Monostearate and Cholesterol based Niosomes for Oral Delivery of Telmisartan. Curr. Drug Deliv. 2018, 15, 260-266. [CrossRef]

35. Unnikrishnan, K.P.; Raja, S.S.; Balachandran, I. A reverse phase HPLC-UV and HPTLC methods for determination of plumbagin inPlumbago indicaandPlumbago zeylanica. Indian J. Pharm. Sci. 2008, 70, 844-847. [CrossRef] [PubMed]

36. Sabitha, M.; Rejinold, N.S.; Nair, A.; Lakshmanan, V.-K.; Nair, S.V.; Jayakumar, R. Development and evaluation of 5-fluorouracil loaded chitin nanogels for treatment of skin cancer. Carbohydr. Polym. 2013, 91, 48-57. [CrossRef]

37. Pierre, M.B.R.; Tedesco, A.C.; Marchetti, J.M.; Bentley, M.V.L. Stratum corneum lipids liposomes for the topical delivery of 5-aminolevulinic acid in photodynamic therapy of skin cancer: Preparation and in vitro permeation study. BMC Dermatol. 2001, 1, 5. [CrossRef]

38. Bhattamisra, S.K.; Shak, A.T.; Xi, L.W.; Safian, N.H.; Choudhury, H.; Lim, W.M.; Shahzad, N.; Alhakamy, N.A.; Anwer, K.; Radhakrishnan, A.K.; et al. Nose to brain delivery of rotigotine loaded chitosan nanoparticles in human SH-SY5Y neuroblastoma cells and animal model of Parkinson's disease. Int. J. Pharm. 2020, 579, 119148. [CrossRef] [PubMed]

39. Singh, D.P.; Prabha, R.; Verma, S.; Meena, K.K.; Yandigeri, M. Antioxidant properties and polyphenolic content in terrestrial cyanobacteria. 3 Biotech 2017, 7, 134. [CrossRef] [PubMed]

40. Westh, P. Unilamellar DMPC Vesicles in Aqueous Glycerol: Preferential Interactions and Thermochemistry. Biophys. J. 2003, 84, 341-349. [CrossRef]

41. Gupta, B.; Poudel, B.K.; Pathak, S.; Tak, J.W.; Lee, H.H.; Jeong, J.-H.; Choi, H.-G.; Yong, C.S.; Kim, J.O. Effects of Formulation Variables on the Particle Size and Drug Encapsulation of Imatinib-Loaded Solid Lipid Nanoparticles. AAPS PharmSciTech 2015, 17, 652-662. [CrossRef] [PubMed]

42. Akhter, H.; Ahmad, A.; Ali, J.; Mohan, G. Formulation and Development of CoQ10-Loaded s-SNEDDS for Enhancement of Oral Bioavailability. J. Pharm. Innov. 2014, 9, 121-131. [CrossRef]

43. Ramadon, D.; Wirarti, G.A.; Anwar, E. Novel Transdermal Ethosomal Gel Containing Green Tea (Camellia sinensis L. Kuntze) Leaves Extract: Formulation and In vitro Penetration Study. J. Young- Pharm. 2017, 9, 336-340. [CrossRef]

44. Sakpakdeejaroen, I.; Somani, S.; Laskar, P.; Mullin, M.; Dufès, C. Transferrin-bearing liposomes entrapping plumbagin for targeted cancer therapy. J. Interdiscip. Nanomed. 2019, 4, 54-71. [CrossRef] [PubMed]

45. Tzeyung, A.S.; Md, S.; Bhattamisra, S.K.; Madheswaran, T.; Alhakamy, N.A.; Aldawsari, H.M.; Radhakrishnan, A.K. Fabrication, Optimization, and Evaluation of Rotigotine-Loaded Chitosan Nanoparticles for Nose-To-Brain Delivery. Pharmaceutics 2019, 11, 26. [CrossRef] [PubMed]

46. Subongkot, T.; Wonglertnirant, N.; Songprakhon, P.; Rojanarata, T.; Opanasopit, P.; Ngawhirunpat, T. Visualization of ultradeformable liposomes penetration pathways and their skin interaction by confocal laser scanning microscopy. Int. J. Pharm. 2013, 441, 151-161. [CrossRef]

47. Moolakkadath, T.; Aqil, M.; Ahad, A.; Imam, S.S.; Iqbal, B.; Sultana, Y.; Mujeeb, M.; Iqbal, Z. Development of transethosomes formulation for dermal fisetin delivery: Box-Behnken design, optimization, in vitro skin penetration, vesicles-skin interaction and dermatokinetic studies. Artif. Cells, Nanomedicine, Biotechnol. 2018, 46, 755-765. [CrossRef] [PubMed]

48. Re, R.; Pellegrini, N.; Proteggente, A.; Pannala, A.; Yang, M.; Rice-Evans, C. Antioxidant activity applying an improved ABTS radical cation decolorization assay. Free Radic. Biol. Med. 1999, 26, 1231-1237. [CrossRef] 